\title{
Seasonal coefficient of performance of air-to-air heat pump and energy performance of a building in Poland
}

\author{
Piotr Kowalski ${ }^{1}$, and Paweł Szałański ${ }^{1, *}$ \\ ${ }^{1}$ Department of Air Conditioning, Heating, Gas Engineering and Air Protection, Wroclaw University \\ of Science and Technology, ul. C.K. Norwida 4/6, 50-373 Wroclaw, Poland
}

\begin{abstract}
The article discusses the problem of determining for air heat pumps the seasonal efficiency of energy production necessary to determine the energy performance of a building. On the example of selected Polish cities (Suwalki, Bialystok, Warsaw, Wroclaw, Zielona Gora, Resko, Szczecinek, Koszalin) the influence of climatic conditions on the SCOP of an exemplary air-to-air heat pump and on the result of building energy performance calculations was analysed. SCOPs for each location were determined according to the method of EN 14825. The difference between SCOP for average (A) and colder (C) climates according to EN 14825 was $35.6 \%$. It has been shown that the climate of Polish cities may be similar to both the average climate (A) and the colder climate (C), or they significantly differ from both climates. The most significant difference in SCOP between the analysed cities was obtained for Suwalki and Szczecinek. It was $31.9 \%$ and $31.4 \%$ for the assumed heating season length as for climate (A) and (C) respectively. For the exemplary building in Suwalki, taking SCOP for the average climate (A) and not based on climatic data of Suwalki gives an error of $39.3 \%$ in the calculation of primary energy for heating. For the same locations, the differences in $S C O P$ and $E P$ resulting from the assumption of the heating season length as for the average climate (A) or as for the colder climate (C) were respectively from $2.4 \%$ to $3.3 \%$ and from $-3.4 \%$ to $-2.2 \%$. In diversified Polish climate, assuming the same SCOP values of air heat pumps regardless of location does not allow for their full comparison with devices whose efficiency does not depend on climatic conditions. The authors suggest that when calculating the energy performance of the building, the $S C O P$ should be always determined on the basis of the local climate and the length of the heating season.
\end{abstract}

\section{Introduction}

In Polish regulations [1], heat pumps are considered as highly efficient alternative heat sources. This is due to such treatment of these devices in the EU [2]. However, the Polish

\footnotetext{
*Corresponding author: pawel.szalanski@pwr.edu.pl
} 
conditions differ from the average European conditions. This is due to a different structure of fuel consumption for electricity generation in Poland and Europe [3]. In Poland, greenhouse gas emissions associated with this production is much higher than in other EU countries. This is because of the much greater use of coal and it affects the energy performance of buildings. The energy performance is based on a calculation of primary energy demand for heating, ventilation, domestic hot water and lighting. The energy performance calculation shall also determine the $\mathrm{CO}_{2}$ emissions resulting from the calculated energy consumption. In Poland this value is given only for information reasons. The results of primary energy calculations are compared with the limits specified in the regulations [4]. These provisions are based on EU rules [2]. Meeting these requirements determines the possibility of realising a new building.

Primary energy demand is influenced by the building construction, its technical systems and the energy and fuel sources used in the building [5]. In the field of building construction, its energy performance is influenced by the thermal insulation of building envelope, thermal bridges, thermal capacity, airtightness and glazing of the building [6, 7]. In the field of technical building systems, the type of ventilation installation together with the type of heat recovery, type and efficiency of heating and cooling installation, type and efficiency domestic hot water installation, types and efficiency of heat sources for these installations and the type of lighting are important. When using a heat pump as a heat source for a building, one of the key issues affecting the result of the energy performance calculations is its efficiency. In the case of air compressor heat pumps, their seasonal efficiency is significantly affected by the climatic conditions under which they operate. The outdoor air temperature is particularly important [8-12]. The efficiency of a heat pump is important for the proper determination of the final and primary energy need of a building [13].

Therefore, the article analyses the problem of determining the seasonal coefficient of performance $(S C O P)$ with particular consideration of the impact of climatic data. The analysis was carried out on the example of an air-to-air heat pump.

\section{Influence of efficiency and type of heat source on the energy performance of the building}

Compressor heat pumps are driven by an electric energy. The justification for using them as a highly efficient heat source, apart from their efficiency, is influenced by the method of generating electricity in the power network from which the heat pump is supplied. This relationship is illustrated by the following equation [5]:

where:

$$
Q_{\mathrm{p}, \mathrm{H}}=Q_{\mathrm{k}, \mathrm{H}} \cdot w_{\mathrm{H}}+E_{\mathrm{aux}, \mathrm{H}} \cdot w_{e l}=\frac{Q_{\mathrm{H}, \mathrm{nd}}}{\eta_{\mathrm{H}, \mathrm{tot}}} \cdot w_{\mathrm{H}}+E_{\mathrm{aux}, \mathrm{H}} \cdot w_{\mathrm{el}}, \mathrm{kWh} / \mathrm{a}
$$

$Q_{\mathrm{p}, \mathrm{H}}$ - annual non-renewable primary energy need for heating and ventilation,

$Q_{k, \mathrm{H}}-$ annual final energy need for heating and ventilation,

$Q_{\mathrm{H}, \text { nd }}-$ annual energy need for heating and ventilation,

$E_{\text {aux,H }}-$ annual auxiliary energy need in heating and ventilation systems,

$w_{\mathrm{H}}-$ non-renewable primary energy factor for the energy or fuel supplied to heating system, for an electric heat pump $w_{\mathrm{H}}=w_{\mathrm{el}}$,

$w_{\mathrm{el}}$ - non-renewable primary energy factor for the electric energy, in Poland, e.g. $w_{\mathrm{el}}=3.0$ for electricity from the electricity grid, $w_{\mathrm{el}}=0.0$ for solar energy,

$\eta_{\mathrm{H}, \text { tot }}$ - the total seasonal efficiency of the heating system determined by the equation: 


$$
\eta_{\mathrm{H}, \mathrm{tot}}=\eta_{\mathrm{H}, \mathrm{g}} \cdot \eta_{\mathrm{H}, \mathrm{e}} \cdot \eta_{\mathrm{H}, \mathrm{d}} \cdot \eta_{\mathrm{H}, \mathrm{s}}
$$

where:

$\eta_{H, g}, \eta_{H, e}, \eta_{H, d}, \eta_{H, s}-$ seasonal efficiency of heat generation from the energy carrier or from energy supplied to the heat source; seasonal efficiency of regulation and use of heat in the heated space; seasonal efficiency of heat transfer from the heat source to the heated space; seasonal efficiency of heat accumulation in the capacitive elements of the heating system.

According to [5], the values of $\eta_{\mathrm{H}, \mathrm{d}}, \eta_{\mathrm{H}, \mathrm{s}}$ shall be determined using the calculation method given in [5]. In case of lack of data for this calculation method, the typical values of $\eta_{\mathrm{H}, \mathrm{d}}, \eta_{\mathrm{H}, \mathrm{s}}$ given in [5], shall be used. The value of $\eta_{\mathrm{H}, \mathrm{e}}$ should always be taken from the table given in [5]. The value $\eta_{\mathrm{H}, \mathrm{g}}$ shall be taken from the technical data of the heat source or, in the absence thereof, the typical values given in [5] shall be used. For heat pumps, the seasonal efficiency of heat generation is expressed by the seasonal coefficient of performance $\left(\eta_{\mathrm{H}, \mathrm{g}}=S C O P\right)$. Manufacturers determine the $S C O P$ according to the method specified in EN 14825 [14]. And the values $w_{\mathrm{H}}, w_{\mathrm{el}}$, according to [5], should be taken as the value specified by the energy suppliers or, in the case of lack of such data, the typical values given in [5] should be used.

Values of $Q_{\mathrm{H}, \mathrm{nd}}, \eta_{\mathrm{H}, \mathrm{e}}, \eta_{\mathrm{H}, \mathrm{d}}, \eta_{\mathrm{H}, \mathrm{s}}, E_{\mathrm{aux}, \mathrm{H}}$ may be the same regardless of the heat source used. Changing the heat source changes $w_{\mathrm{H}}$ and SCOP. Therefore, in order to present the influence of the type of heat source on the result of the energy performance calculations, the $w_{\mathrm{H}}$ and $S C O P$ ratio has been defined as:

$$
P P R=\frac{w_{\mathrm{H}}}{S C O P}
$$

For a specific building location and heating parameters, SCOP depends only on the heat pump model. While $w_{\mathrm{H}}$ depends on the type of energy or fuel supplying the heat source and for the heat pump $w_{\mathrm{H}}=w_{\mathrm{el}}$. According to [5], typically $w_{\mathrm{el}}=3.0$ in Poland, whereas according to 2006/32/EC [15], for savings in kWh electricity, Member States may apply a default coefficient of 2.5. Detailed analyses taking into account the types of fuels for electricity production and particular Member States give an even greater variety of values $w_{\mathrm{el}}[16]$.

According to equation (1), assuming constant values of $\eta_{\mathrm{H}, \mathrm{e}}, \eta_{\mathrm{H}, \mathrm{d}}, \eta_{\mathrm{H}, \mathrm{s}}, E_{\mathrm{aux}, \mathrm{H}}$, it can be concluded that the higher the $P P R$, the more difficult it is to meet the regulatory requirements for the maximum allowable need for non-renewable primary energy of the building.

The $P P R$ value for the analysed air-to-air heat pump type, with $S C O P=3.00$ [5], is comparable to $P P R$ for conventional heat sources (Table 1). However, the SCOP values declared by producers are significantly higher than in [5]. Usually they provide only SCOPS determined on the basis of standard EN 14825 [14] and climatic data specified therein for an average climate (A). In order to justify the adoption of the values provided by producers, it is important to determine to what extent the average climate corresponds to the Polish climate. This is particularly important because assuming a low SCOP value on the basis of [5] can make it impossible to meet the requirements for the energy performance of a building. On the other hand, unjustified adoption of SCOP on the basis of manufacturer's data for the average climate (A) may underestimate the demand for non-renewable primary energy need. This issue is explained further in the article. 
Table 1. Comparison of $P P R$ values for different heating systems based on typical values $\eta_{\mathrm{H}, \mathrm{g}}$ or $S C O P$ and $w_{\mathrm{H}}$ from [5].

\begin{tabular}{|c|c|c|c|}
\hline Heat source type & $\boldsymbol{w}_{\mathbf{H}}$ & $\begin{array}{c}\boldsymbol{\eta}_{\mathbf{H , g}} \text { or } \\
\boldsymbol{S C O P}\end{array}$ & $\boldsymbol{P P R}$ \\
\hline $\begin{array}{c}\text { District heating station up to 100 kW, powered by heat from a } \\
\text { hard coal-fired cogeneration source }\end{array}$ & 0.8 & 0.91 & 0.88 \\
\hline Solid fuel boiler (hard coal) & 1.1 & 0.82 & 1.34 \\
\hline Automatic biomass boiler up to 100 kW & 0.2 & 0.70 & 0.29 \\
\hline Condensing gas boilers $\left(55 / 45^{\circ} \mathrm{C}\right)$ of nominal output up to $50 \mathrm{~kW}$ & 1.1 & 0.94 & 1.17 \\
\hline $\begin{array}{c}\text { Electrically driven brine-to-water compressor heat pumps } \\
\left(55 / 45^{\circ} \mathrm{C}\right)\end{array}$ & 3.0 & 3.50 & 0.86 \\
\hline $\begin{array}{c}\text { Electrically driven brine-to-water compressor heat pumps } \\
\left(35 / 28^{\circ} \mathrm{C}\right)\end{array}$ & 3.0 & 4.00 & 0.75 \\
\hline Electrically driven air-to-air compressor heat pumps & 3.0 & 3.00 & 1.00 \\
\hline
\end{tabular}

\section{Poland's climate compared to EN 14825}

The SCOP value of air-to-air heat pumps is very dependent on the outdoor air parameters and the frequency of their occurrence in the given region. This raises the fundamental question of how to properly determine the SCOP value taking into account local climatic conditions and what error is being made without taking these climatic data into account.

\subsection{Types of climate according to EN 14825 [5]}

The standard [14] specifies how to determine the SCOP for the following climates:

- average (A),

- warmer (W),

- colder (C).

Each of these climates is characterized by the frequency of particular outdoor air temperatures. These frequencies are given in Annex A of standard [14]. They were determined on the basis of climatic data of selected cities, respectively for climate [14]:

- average - Strasbourg,

- warmer - Athens,

- colder - Helsinki.

On the basis of climatic data given in the standard [14] for particular types of climate, graphs of cumulative frequencies of outdoor air temperatures were prepared (Figure 1).

\subsection{Climate of selected Polish cities}

The standard [14] specifies that it is necessary to determine the SCOP only for the average climate (A). It is not clear whether this type of climate corresponds to Polish conditions. Therefore, for selected Polish cities graphs of cumulative frequencies of outdoor air temperatures were presented on Figure 1. It was prepared on the basis of generally available climatic data [17] for Suwalki, Bialystok, Warsaw, Wroclaw, Zielona Gora, Resko, Szczecinek, Koszalin used in Poland for the calculation of energy performance of buildings. These frequencies were determined by rounding the temperature values to integers. The standard [14] does not provide information on the length of analysed periods 
of the year for particular types of climate. Therefore, these periods were adopted on the basis of report [18]:

- from the beginning of September to the end of May - for the colder climate (C),

- from the beginning of October to the end of April - for the average climate (A).

Outdoor air temperatures below $16^{\circ} \mathrm{C}$ have been taken into account.

In order to determine which climate suits a particular city, the length of the heating season for each of the cities was assumed in two variants. Figure 1 presents the cumulative frequencies of outdoor air temperatures for the assumed heating season length as for the average climate (A) and as for the colder climate (C), respectively.
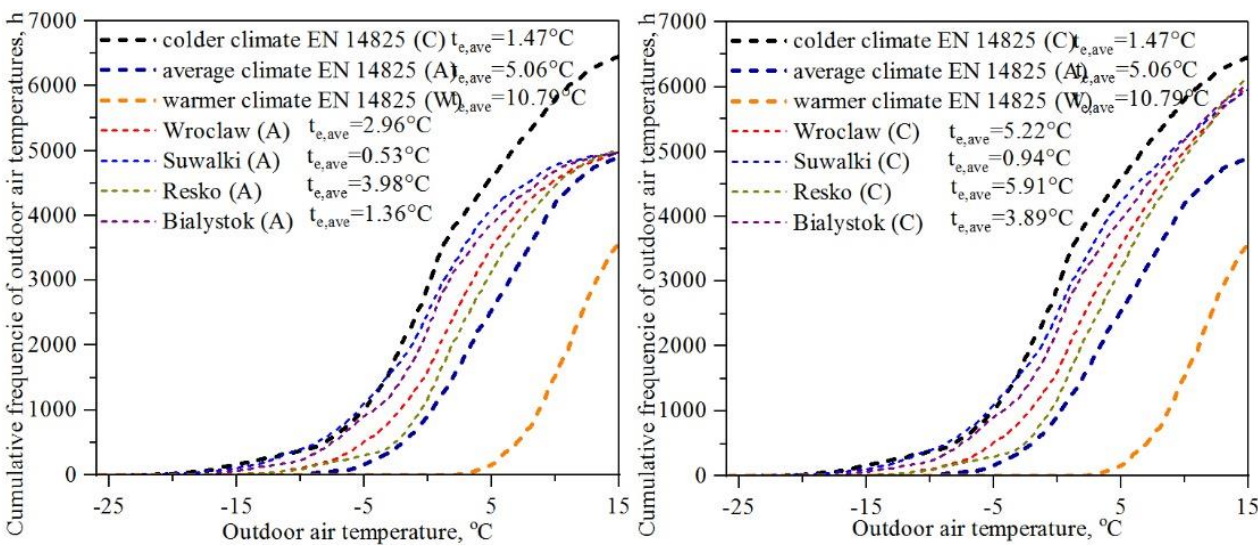

Fig. 1. Cumulative frequencies of outdoor air temperatures for the assumed length of the season as for the average climate $(\mathrm{A})$ - on the left and as for the colder climate $(\mathrm{C})$ - on the right.

\section{Influence of climate data on SCOP and energy performance of the building}

The following is an analysis of the impact of the source of the heat pump's SCOP value on the result of the energy performance of the building calculations $(E P)$. The results obtained on the basis of SCOP from the manufacturer's data and SCOP determined taking into account climatic data were compared.

\subsection{Assumptions}

The analysis was carried out with the following assumptions:

- SCOP values were determined using the method described in EN 14825 [14] and based on the technical data of the selected air-to-air heat pump,

- the analysis was carried out for a residential building with an area of $90.3 \mathrm{~m}^{2}$, detached, single-storey, with a flat roof and windows with an area of $4.14 \mathrm{~m}^{2}$ on each façade,

- the design heat load of a building heated with an air-to-air heat pump is $3.60 \mathrm{~kW}$ at the outdoor air temperature $t_{\mathrm{e}}=-15^{\circ} \mathrm{C}$, under these conditions the power of the heat pump is $3.05 \mathrm{~kW}$ and the power of the auxiliary electric heater is $0.55 \mathrm{~kW}$,

- at outdoor air temperature of $-15^{\circ} \mathrm{C}$ (temperature operating limit), $-7^{\circ} \mathrm{C}$ (bivalent point), $2^{\circ} \mathrm{C}, 7^{\circ} \mathrm{C}, 12^{\circ} \mathrm{C}$ the reversible heat pump capacity (for analysed building) equals respectively $2.84 \mathrm{~kW}, 3.18 \mathrm{~kW}, 1.94 \mathrm{~kW}, 1.25 \mathrm{~kW}, 1.09 \mathrm{~kW}$ and $C O P$ equals respectively $2.33,2.85,4.95,6.42,7.79$, 
- the device changes from continuous operation to ON/OFF operation with less than $30 \%$ load,

- the length of the heating season was assumed in two variants: as for the average climate (A) and as for the colder climate (C), as described in point 3.2.

\subsection{Results}

In particular variants of calculations only climatic data were changed. The SCOPs were calculated for climatic data given in EN 14825 [14] for the average (A), the colder (C) and the warmer climate (W) and for climatic data of selected Polish cities: Suwalki, Bialystok, Warsaw, Wroclaw, Zielona Gora, Resko, Szczecinek, Koszalin [17]. The results of the analysis are presented in Tables 2 and 3.

Table 2. Result of energy performance of the building, SCOP and $P P R$ calculations based on Polish climatic data [17].

\begin{tabular}{|c|c|c|c|c|c|c|c|c|c|}
\hline \multicolumn{2}{|c|}{} & Suwalki & Bialystok & Warsaw & Wroclaw & $\begin{array}{c}\text { Zielona } \\
\text { Gora }\end{array}$ & Resko & Szczecinek & Koszalin \\
\hline $\begin{array}{c}S C O P / \\
P P R\end{array}$ & $(\mathrm{~A})$ & $3.27 / 0.92$ & $3.61 / 0.83$ & $4.44 / 0.68$ & $4.15 / 0.72$ & $4.43 / 0.68$ & $4.40 / 0.68$ & $4.51 / 0.67$ & $4.50 / 0.67$ \\
\cline { 2 - 9 } & (C) & $3.38 / 0.89$ & $3.73 / 0.81$ & $4.55 / 0.66$ & $4.27 / 0.70$ & $4.54 / 0.66$ & $4.52 / 0.66$ & $4.64 / 0.65$ & $4.61 / 0.65$ \\
\hline $\begin{array}{c}\mathrm{EPH}^{(1)} \\
\mathrm{kWh} \\
/\left(\mathrm{m}^{2} \cdot \mathrm{a}\right)\end{array}$ & (A) & 80.6 & 64.8 & 39.8 & 41.1 & 41.5 & 39.3 & 40.8 & 41.2 \\
\cline { 2 - 9 } & 77.9 & 62.7 & 38.8 & 40.0 & 40.5 & 38.2 & 39.6 & 40.3 \\
\hline
\end{tabular}

$\mathrm{EP}_{\mathrm{H}}$ - indicator of non-renewable primary energy use for heating and ventilation, $\mathrm{kWh} /\left(\mathrm{m}^{2} \cdot \mathrm{a}\right)$

Table 3. Result of energy performance of a building calculations based on Polish climatic data [17] and on SCOP determined on the basis of climatic data from [14].

\begin{tabular}{|c|c|c|c|c|c|c|c|c|c|c|}
\hline \multicolumn{2}{|c|}{} & $\begin{array}{c}\text { SCOP/PPR } \\
\text { according to } \\
\text { EN 14825 }\end{array}$ & Suwalki & Bialystok & Warsaw & Wroclaw & $\begin{array}{c}\text { Zielona } \\
\text { Gora }\end{array}$ & Resko & Szczecinek & Koszalin \\
\hline \multirow{2}{*}{$\begin{array}{c}\mathrm{EP}_{\mathrm{H}}^{(2)} \\
\mathrm{kWh} \\
/\left(\mathrm{m}^{2} \cdot \mathrm{a}\right)\end{array}$} & $(\mathrm{W})$ & $6.51 / 0.46$ & - & - & - & - & - & - & - & - \\
\cline { 2 - 12 } & $(\mathrm{A})$ & $4.87 / 0.62$ & 54.1 & 48.1 & 36.2 & 35.0 & 37.8 & 35.5 & 37.8 & 38.1 \\
\hline
\end{tabular}

\subsection{Discussion of results}

The results of the analysis show that the $S C O P$ and $P P R$ values calculated for the average (A) and for the colder climate (C) on the basis of climatic data given in EN 14825 [14] are significantly different. The difference is $35.6 \%$ in relation to the average of these values.

Among the analysed cities located in Poland, one can indicate those whose climatic data are similar to the average climate (A) and those which are similar to the colder climate (C). Thus, it cannot be stated which climatic data given in [14] are appropriate for the whole area of Poland. The highest differences in SCOP and PPR were obtained between the values for Suwalki and Szczecinek. These differences are $31.9 \%$ and $31.4 \%$ for climate (A) and (C), respectively. These percentages were obtained by dividing the value difference for both cities by the average of these values.

The SCOP and PPR values obtained for particular locations are also influenced by the assumed length of the heating season to calculate the frequency of outdoor air temperatures. These differences are much smaller than those resulting from the effect of changing the location of the building. However, the change in the length of the heating season from such 
as for the average climate (A) to such as for the colder climate $(\mathrm{C})$ causes a change in $S C O P$ of $2.4 \%$ to $3.3 \%$ and in $E P$ of $-3.4 \%$ to $-2.2 \%$ in relation to the average in both cases.

Differences in SCOP and $P P R$ values are transferred to differences between $\mathrm{EP}_{\mathrm{H}}$ values for different locations and climates. Table 4 shows the differences between $\mathrm{EP}_{\mathrm{H}}$ values obtained by two methods:

- based on SCOP calculated according to Polish climatic data [17] (Table 2),

- based on SCOP calculated according to climatic data from EN 14825 [14] (Table 3).

Table 4. Percentage differences between $\mathrm{EPH}$ values presented in the tables 2 and 3

\begin{tabular}{|c|c|c|c|c|c|c|c|c|c|}
\hline \multicolumn{2}{|l|}{} & Suwalki & Bialystok & Warsaw & Wroclaw & $\begin{array}{c}\text { Zielona } \\
\text { Gora }\end{array}$ & Resko & Szczecinek & Koszalin \\
\hline$\frac{\left|E P_{H}^{(1)}-E P_{H}^{(2)}\right|}{\left(E P_{H}^{(1)}+E P_{H}^{(2)}\right) / 2}$ & (A) & $39.3 \%$ & $29.7 \%$ & $9.2 \%$ & $16.0 \%$ & $9.5 \%$ & $10.1 \%$ & $7.7 \%$ & $7.9 \%$ \\
\hline
\end{tabular}

The differences presented in Table 4 show that the climate of Polish cities is similar both to the average climate (A) - Szczecinek, Koszalin and the colder one (C) - Suwalki, Bialystok. The climates of other cities are significantly different from both the climate (A) and $(\mathrm{C})$.

\section{Conclusions}

The assuming of too short heating season significantly reduces the frequency of higher outdoor air temperatures characteristic for the beginning and end of the heating season (Figure 1). The comparison shown in Table 2 shows that assuming a longer heating period, characteristic for the colder climate $(\mathrm{C})$, results in higher SCOP values than for the shorter season, characteristic for the average climate (A). This is due to the fact that the performance and capacity of air heat pumps increases with the increase of outdoor air temperature.

The authors suggest that the length of the heating season used to determine the frequency of outdoor air temperatures, which is then used to determine the $S C O P$, should coincide with the season length calculated when calculating the energy performance of the building based on EN ISO 13790 [7] (Figure 2).

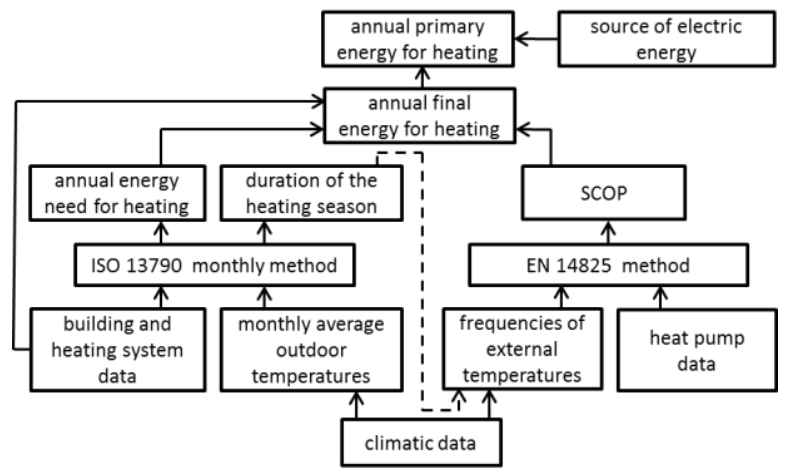

Fig. 2. Proposed scheme for the energy performance calculations with SCOP based on local climate.

This means that the SCOP of the same air-to-air heat pump will depend on both the construction (i.e. insulation, thermal bridges, glazing) of the building and its location. Taking SCOPs given by producers, without taking into account the local climate, can significantly change the result of the energy performance calculations (Tables 3 and 4). 
Taking into account the variety of the Polish climate, assuming the same SCOP values for devices whose performance depends on outdoor conditions does not allow for a full comparison of buildings equipped with these devices with other buildings equipped with devices whose efficiency does not depend significantly on climate conditions. Taking into account the differences shown in the article and their impact on the SCOP values, and thus on the energy performance of the building, the SCOP should be determined each time, taking into account the local climate and the length of the heating season determined for the analysed building.

\section{References}

1. Minister of Transport, Construction and Maritime Economy, Regulation on the detailed scope and form of a construction project (25 April, 2012)

2. European Parliament and The Council of the European Union, Directive 2010/31/EU on the energy performance of buildings (recast) (19 May 2010)

3. Eurostat Electricity generation statistics - first results, https://ec.europa.eu/eurostat/ statistics-explained/index.php?title=Electricity_generation_statistics___first_results\# Production_of_electricity [Accessed: 3 Apr 2019]

4. Minister of Infrastructure and Economic Development, Regulation on the technical conditions, which are to be met by buildings and their location (12 April, 2002)

5. Minister of Infrastructure and Economic Development, Regulation on the methodology for determining the energy performance of building or part of the building and energy performance certificates (21 February, 2015)

6. P. Kowalski, P. Szałański, E3S Web of Conferences 44, 00078 (2018)

7. EN ISO 13790:2008 Energy performance of buildings - Calculation of energy use for space heating and cooling

8. P. Vocale, M. Spiga, Energy Procedia, 45 (2014)

9. M. Dongellini, C. Naldi, G. L. Morini, Energy Procedia, 78 (2015)

10. C. Naldi, M. Dongellini, G. L. Morini, Energy Procedia, 81 (2015)

11. M. Dongellini, C. Naldi, G. L. Morini, Appl. Therm. Eng. 90 (2015)

12. K. Piechurski, M. Szulgowska-Zgrzywa, Rynek Instal. 24, 10 (2016)

13. P. Kowalski, P. Szałański, E3S Web of Conferences 17, 00045 (2017)

14. EN 14825:2012 Air conditioners, liquid chilling packages and heat pumps, with electrically driven compressors, for space heating and cooling - Testing and rating at part load conditions and calculation of seasonal performance

15. European Parliament and The Council of the European Union, Directive 2006/32/EC on energy end-use efficiency and energy services and repealing Council Directive 93/76/EEC (5 April 2006)

16. U. R. Fritsche, H.-W. Greß, Development of the Primary Energy Factor of Electricity Generation in the EU-28 from 2010-2013 (2015)

17. Ministry of Infrastructure and Building, Typical statistical climate data for the Polish area for building energy performance purposes., http://mib.gov.pl/2Wskazniki_emisji_wartosci_opalowe_paliwa.htm) [Accessed: 26 January, 2017]

18. Armines, Final report of Task 6. Air conditioning systems. Lot 6: Air-conditioning and ventilation systems Sustainable Industrial Policy - Building on the Ecodesign Directive - Energy-Using Product Group Analysis/2 (July 2012) 